\title{
Hand Hygiene Facilities in the Clinical Laboratories of a Tertiary Health Facility in a Lassa Fever Endemic Country
}

\author{
Olusegun Adesola Busari ${ }^{1, ~ *}$, Opeyemi James Oje ${ }^{2}$, Babajide Adeleke ${ }^{3}$, Olusogo Ebenezer Busari ${ }^{1}$, \\ Olusegun Emanuel Gabriel ${ }^{4}$, Segun Matthew Agboola ${ }^{4}$, Adebara Idowu Oluseyi ${ }^{5}$ \\ ${ }^{1}$ College of Medicine and Health Sciences, Afe Babalola University, Ado-Ekiti, Nigeria \\ ${ }^{2}$ Department of Food Technology, Federal Polytechnic, Ado-Ekiti, Nigeria \\ ${ }^{3}$ Department of Chemical Pathology, Federal Teaching Hospital, Ido-Ekiti, Nigeria \\ ${ }^{4}$ Department of Family Medicine, Federal Teaching Hospital, Ido-Ekiti, Nigeria \\ ${ }^{5}$ Department of Obstetrics and Gynaecology, Federal Teaching Hospital, Ido-Ekiti, Nigeria
}

Email address:

olubusari@yahoo.com (O. A. Busari)

${ }^{*}$ Corresponding author

\section{To cite this article:}

Olusegun Adesola Busari, Opeyemi James Oje, Babajide Adeleke, Olusogo Ebenezer Busari, Olusegun Emanuel Gabriel, Segun Matthew Agboola, Adebara Idowu Oluseyi. Hand Hygiene Facilities in the Clinical Laboratories of a Tertiary Health Facility in a Lassa Fever Endemic Country. American Journal of Laboratory Medicine. Vol. 3, No. 2, 2018, pp. 25-29. doi: 10.11648/j.ajlm.20180302.11

Received: February 1, 2018; Accepted: April 8, 2018; Published: July 17, 2018

\begin{abstract}
Hand hygiene is a general term referring to any action of hand cleansing. It basically includes hand washing and hand rubbing. It is considered the most important simple measure for preventing the spread of pathogens generally and particularly in health-care setting. The objective of the survey was to evaluate the availability and accessibility of hand hygiene facilities in the clinical laboratories of a tertiary health facility in south west Nigeria. A previously used survey checklist assessing the condition of sink and other hand hygiene facilities in a health care setting was further modified and employed for data collection. Descriptive data analysis was done by calculating the frequencies. There were sixteen sinks in the laboratories where the survey was conducted. All the sixteen sinks were accessible to the users and were physically intact. Four (25\%) of the sinks had damaged draining pipes. Half of the sinks had hand-held faucet. There was no sink with automated faucet. None of the faucets had water flowing when turned on at the time of the survey. Also, none had water flowed through it in the past 72 hours prior the survey according to users' interview. Soap was available in only $6(37.5 \%)$ of the sinks and there was no hand $\mathrm{rub} /$ hand disinfectant or hand drying materials available. The survey has shown that there was a gross lack of hand hygiene facilities in the clinical laboratories of the tertiary health facility. There is an urgent need for critical stakeholders in the health sector to give policy and financial priority to provision of adequate modern hand hygiene facilities in all health care settings.
\end{abstract}

Keywords: Hand Hygiene Facilities, Clinical Laboratories, Hospital-Acquired Infections, Lassa Fever Endemic Setting

\section{Introduction}

Hand hygiene $(\mathrm{HH})$ is a general term referring to any action of hand cleansing. It basically includes hand washing and hand rubbing [1]. Hand washing is defined as a vigorous, brief rubbing together of all surfaces of hands with water and soap or other detergents containing an antiseptic agent, followed by rinsing under a stream of water [1]. Hand rubbing is applying a waterless antiseptic hand rub to reduce or inhibit the growth of microorganisms without the need for an exogenous source of water and requiring no rinsing or drying with towels or other devices [1]. HH is considered the most important simple measure for preventing the spread of pathogens generally and particularly in health-care setting (HCS) [2-4]. Lassa fever is an extremely virulent and infectious viral haemorrhagic fever that occurs very frequently in different parts of Nigeria and affects about 100,000-500,000 persons per year [5-8].

In West Africa, Lassa virus is a zoonotic disease and infected rodents in the mastomysnatalensis species complex 
are reservoirs capable of excreting the virus through urine, saliva, excreta, and other body fluids. Nosocomial transmission is also not uncommon [9-13].

In the HCS, a prospective controlled trial in a hospital nursery and research conducted in the past 40 years have confirmed the critical link between poor $\mathrm{HH}$ practices and transmission of health care associated pathogens [4, 14]. In the community, $\mathrm{HH}$ has been acknowledged as an important measure to prevent and control infectious diseases and can significantly reduce the burden of disease, particularly among children in developing countries [15-18]. Clinical laboratory is an important physical and functional integral component of an effective HCS. Clinical laboratory is a laboratory where tests are done on clinical specimens to provide additional information about the health of patients in terms of supporting diagnosis, treatment and prevention of disease. $\mathrm{HH}$ is part of the infection control mechanisms in clinical laboratory and in the health facility where health care workers (HCW) are at risk of exposure to potentially infectious materials [19-23]. HH with soap and water has been considered a measure of personal hygiene for centuries but the link between it and the spread of disease has only been established in the last 200 years [24, 25]. In the mid 1800 s, studies by Ignaz Semmelweis in Vienna and Oliver Wendell Holmes in Boston established that some hospitalacquired diseases, not known to be caused by infectious agents, were transmitted through poor $\mathrm{HH}$ practices $[2,26]$. However, as simple and important $\mathrm{HH}$ is, poor practices are commonplace in HCS, particularly in developing countries where $\mathrm{HH}$ infrastructure is also lacking [2, 27-30]. In resource constraint settings, inadequate access to soap and water, alcohol-based solutions, and limited provision of sinks are major hindrances to performing $\mathrm{HH}$ at the points of care and services in HCS $[31,32]$. To the best of the authors' search, there is very little research and documentation on $\mathrm{HH}$ facilities in the clinical laboratories of hospitals in Nigeria and Africa at large. The objective of the survey was to evaluate the availability and accessibility of $\mathrm{HH}$ facilities in the clinical laboratories of a tertiary health facility in south west Nigeria. This is a country plagued by infectious diseases and where Lassa was first diagnosed in 1969 and which has since experienced repeated outbreaks with case fatality of $37.9 \%$.

\section{Materials and Methods}

The survey was conducted in the clinical laboratories of a tertiary health facility in Southwest Nigeria. The clinical laboratory departments were: Haematology and Blood Transfusion, Microbiology and Parasitology, Chemical Pathology and Immunology, and Morbid Anatomy and Histopathology. The study protocol was approved by the Research Ethics Committee of the facility. A previously used survey checklist assessing the condition of sinks and other $\mathrm{HH}$ facilities in a HCS was further modified and employed for data collection [2]. The conduct of the survey was a direct observation of $\mathrm{HH}$ facilities in the laboratories mentioned above by Principal Investigator. Descriptive data analysis was done by calculating the frequencies.

Table 1. Modified checklist for survey of HH facilities in clinical laboratories.

\begin{tabular}{|c|c|}
\hline Accessibility of sink & $\begin{array}{l}\text { Accessible/not accessible (including faulty design of Space/blocked by } \\
\text { object/not in work environment) }\end{array}$ \\
\hline Physical condition of the sink & Intact/Damaged \\
\hline Condition of the sink draining pipe & Intact/Damaged (including broken/blocked) \\
\hline Type of faucet & Hand/Elbow/Automated \\
\hline Is water flowing from the faucet? & Yes/No \\
\hline If 'No' to above, has it flowed in the last 72 hours? & Yes/No \\
\hline Availability of soap & Yes/No \\
\hline Availability of hand rubs/disinfectant & Yes/No \\
\hline If 'Yes' to above, what type? & Alcohol-based/Non-alcohol \\
\hline Availability of hand drying facilities & Yes/No \\
\hline If 'Yes' to above, what type? & Paper towel/Cloth towel/Automated hand dryer \\
\hline Availability of hand hygiene instruction demonstrating standard techniques & Yes/No \\
\hline
\end{tabular}

\section{Results}

There were sixteen sinks in the laboratories where the survey was conducted. All the sixteen sinks were accessible to the users and were physically intact. Four $(25 \%)$ of the sinks had damaged draining pipes. The results of the survey are highlighted in Table 2. Half of the sinks used hand held faucet. There was no automated faucet. None of the faucets had water flowing through it at the time the survey was conducted (Table 2). Also, none had water flowed through it in the previous 72 hours before the survey according to the interview with the HCW. Soap was available in only 6 $(37.5 \%)$ of the sinks and it was in liquid preparation inside bottle dispensers. There was no hand rub/ hand disinfectant available. No hand drying materials and no electric hand dryer. None of the sinks had instructions on HH techniques pasted beside it or at any other place in the laboratories.

Table 2. Results of HH facilities in clinical laboratories.

\begin{tabular}{lll}
\hline Total number of sinks surveyed & & $\mathbf{1 6}$ \\
\hline Sinks & Accessible & $16(100 \%)$ \\
& Intact & $16(100 \%)$ \\
& Intact drain & $12(75 \%)$ \\
& Damaged drain & $4(25 \%)$ \\
\hline
\end{tabular}




\begin{tabular}{lll}
\hline Total number of sinks surveyed & & $\mathbf{1 6}$ \\
\hline Faucet & Hand held & $8(50 \%)$ \\
& Elbow operated & $8(50 \%)$ \\
& Automated & - \\
& Water flowing & - \\
& Water not flowing & $16(100 \%)$ \\
Soap Availability & Yes & $6(37.5 \%)$ \\
& No & $10(62.5 \%)$ \\
Handrub Availability & Yes & - \\
& No & $16(100 \%)$ \\
Hand drying facilities & Yes & - \\
Availability & No & $16(100 \%)$ \\
Hand hygiene instructions & Yes & - \\
Availability & No & $16(100 \%)$ \\
\hline
\end{tabular}

\section{Discussion}

$\mathrm{HH}$ is an important component of the infection control mechanisms in the HCS including the clinical laboratories where $\mathrm{HCW}$ are at risk of exposure to potentially infectious blood, body fluids and secretions, and body tissues [19-23]. Safety is a key word in a clinical laboratory setting, and effective $\mathrm{HH}$ practices promoted by availability and accessibility of $\mathrm{HH}$ facilities are essential to achieving it. High standard of hygiene are required in the laboratories for all procedures involving microbiological specimens and cultures, and with body substances and fluids. The survey showed that all the sinks in the laboratories were accessible by the users. Accessibility of $\mathrm{HH}$ facilities and supplies by the HCW in terms of relative location and distance to the points of services and whether or not they are obstructed by other facilities or equipment have been shown to be an important risk factor for poor adherence to $\mathrm{HH}[30,33,34]$. Although the body of all the sinks observed was physically intact, $75 \%$ of them had damaged draining pipes. This is similar to the findings of a previous study by Busari et al in the same facility but clinical points of care [2].

The survey also revealed that half of the faucets for the sinks were hand operated and none of them had water flowing through when opened. In addition, from the interview with the users, no water had flowed in the last 72 hours before the survey was conducted. The finding of hand operated faucets is not different from several reports from studies conducted in other resource-constraint settings in developing countries $[30,35,36]$. The use of hand held faucet can predispose to recontamination of the hands from faucet' handles as it was observed during a Shigella sonnei outbreak in a clinical microbiology laboratory [37]. Having a sink without water flowing through the faucet negates the very foundation of hand washing. The survey found that buckets of water were provided beside the sinks with bowls and/or cups to take water whenever hand washing is to be done. Obviously, there are many flaws in these processes which encourage multiple contacts of contaminated hands with objects which are supposed to serve as media for hand washing. Therefore the washed hands might not be effective or might become re-contaminated.

In the survey, soap availability was $37.5 \%$ and there was no handrub products. These findings are consistent with reports by Busari et al and in contrast to findings by Devlani et al, Kesavan et al and Caniza et al [2, 32, 35, 38]. A hand rub is a waterless alcohol-based compound that is used as a rub or rinse for hands. Hand rubs kill microorganisms but do not remove soil or organic material and they are not an option if hands are visibly soiled. No sink and water are necessary, and the dispenser can easily be mounted at care points or any service areas in the laboratory. There have been several studies comparing hand washing with the use of hand rub in HCS [30, 39-41]. The main pitfall of hand washing is the poor compliance by $\mathrm{HCW}$ in situations in which hand washing is necessary. However, the use of hand rubs has been found to be very crucial to improvement of compliance with $\mathrm{HH}$ in clinical settings. Other aspects where the use of hand rubs may be better than hand washing are: more antimicrobial efficacy, shorter time of procedure, and less potential for recontamination by water or soap particularly in low socioeconomically, resource-constraint settings [37]. The US National Guidelines on Hand Hygiene recommends HH with soap and water as the standard of care and waterless antiseptic hand rubs only in situations where sinks are not available [42-44]. The WHO Infection Control Guidelines also suggest that $\mathrm{HH}$ can be performed by either hand washing or hand rubbing, but without stating any advantage of one over the other [45, 46]. However, the Centre for Disease Control and Prevention (CDC)/Healthcare Infection Control Practices Advisory Committee (HICPAC) Guidelines issued in 2002 defined alcohol-based hand rubbing as the standard of care for $\mathrm{HH}$ practices in health-care settings [4].

Finally, the survey also showed that there was neither hand drying materials nor $\mathrm{HH}$ instructions available with the sinks or near them in any of the laboratories. This corroborates the findings of the study by Alex-Hart et al that disposable paper towel and electric hand dryer were not available for $\mathrm{HH}$ in most of the wards of the hospital [47]. Hand drying is an essential step in hand washing and should be done in a way that hand re-contamination does not occur [48]. Although, hand drying should ideally be done using individual disposable paper towels, there are other methods such as cloth towels and electric air dryers [49]. The report of a study that compared four methods of hand drying: cloth towels from a roller; paper towel left on a sink; electric air dryer; and letting hands dry by evaporation; showed no significant difference in the efficacy of the methods [50]. However, reusing or sharing cloth towels should be avoided because of the risk of cross-infections [51]. Electric air dryer requires longer time to achieve dry hands with a possible negative impact on $\mathrm{HH}$ compliance; and performs worse than drying with paper towel in terms of ability to remove bacteria from washed hands [49].

\section{Conclusion}

The survey has shown that there was a lack of $\mathrm{HH}$ facilities in the clinical laboratories of the tertiary health facility. This is worrisome in a country endemic for several infectious diseases, including Lassa fever. If the very basic 
health infrastructure such as $\mathrm{HH}$ facilities is inadequate and antiquated, then modern hospital facilities are going to be absent. There is an urgent need for critical stakeholders in the health sector to give policy and financial priority to provision of adequate modern hand hygiene facilities in all health care settings in the country. Also, practical emphasis should be placed on establishment of effective infection control unit in each health facility and in the Department or Ministry of Health to formulate and implement policies on infection control.

\section{References}

[1] WHO Guidelines on Hand Hygiene in Health Care (Advanced Draft). Part of the WHO Consultation on Hand Hygiene in Health Care Global Patient Safety Challenge, 2005-2006: Clean Care is Safer Care. Geneva, 2006.

[2] Busari OA, Agboola MS, Oyekale OT, Ojo OM, Oje OJ, Oladosu YO. A survey of hand hygiene facilities in a tertiary hospital in Nigeria. TAF Preventive Medicine Bulletin 2012; 11 (5): 571-576.

[3] Beggs CB, Noakes CJ, Shepherd SJ, Kerr KG, Sleigh PA, Banfield $\mathrm{K}$. The influence of nurse cohorting on hand hygiene effectiveness. Am J Infect Control 2006; 34: 10: 621-626.

[4] Boyce JM et al. Guidelines for hand hygiene in health care settings. Recommendations of the Healthcare Infection Control Practices Advisory Committee and the HICPAC/SHEA/APIC/IDSA Hand Hygiene Task Force. Society for Healthcare Epidemiology of America/Association for Professionals in Infection Control/Infectious Diseases Society of America. Morbidity and Mortality Weekly Report 2002; 51 (RR-16): 1-45.

[5] Omilabu SA, Badaru SO, Okokhere P, Asogun D, Drosten C, Emmerich P. Lassa fever in Nigeria. Emerg Infect Dis 2005, 11 (10): 1642-1644.

[6] Ogbu O, Ajuluchukwu E, Uneke CJ. Lassa fever in West Africa sub-region: an overview. J Vect Borne Dis 2007; 44 (1): $1-11$.

[7] Bowen MD, Rollin PE, Ksaizek TG, Hustard HL, Bausch DG, Demby AH. Genetic diversity among Lassa virus strains. J Virol. 2000; 74 (15): 6992-7004.

[8] Fichet-Calvet E, Rogers DJ. Risk maps of Lassa fever in West Africa. PLOS Negl Trop Dis 2008; 3:388.

[9] Centre for Disease Control and Prevention. Lassa fever fact sheet; 2014. Available: http://www.cdc.gov/ncidod/dvrd/spb/mnpages/dispages/factsh eets/lassa_fever_fact_sheet.pdf. Accessed January 20018.

[10] World Health Organization. World Health Organization fact sheet on Lassa fever. 2015; 10 (11).

[11] Eze KC, Salami TAT, Eze IC, Pogoson AE, Omordia N, Ugochukwu MO. High Lassa fever activity in Northern part of Edo state, Nigeria: re-analysis of confirmatory test results. Afr J Health Sci 2010; 17: 52-56.

[12] Fischer-Hosch SP, Tomori O, Nasidi A, Perez-Oronoz GI, Fakile Y. Hutwagner L, McCormick JB. Review of cases of nosocomial Lassa fever in Nigeria: the high price of poor medical practice. BMJ 1995; 30: 311: 857-9.

[13] Kennyyside RA, McCormick JB, Webb PA, Smith E, Elliot L, Johnson KM. Case-control study of Mastomysnatalensis and humans in Lassa virus-infected households in Sierra Leone. Am J Trop Med Hyg 1983; 32: 829-37.

[14] Mortimer EA, Jr, Lipsitz PJ, Wolinsky E, et al. Transmission of staphylococci between newborns. Importance of the hands of personnel. Am J Dis in Children 1962; 104: 289-95.

[15] Aiello AE et al. What is the evidence for a causal link between hygiene and infections? Lancet Infectious Diseases 2002; 2: $103-110$

[16] Luby SP et al. Effect of intensive hand washing promotion on childhood diarrhoea in high-risk communities in Pakistan: a randomized controlled trial. JAMA 2004; 291: 2547-54.

[17] Luby SP et al. The effect of hand washing on child health: a randomized controlled trial. Lancet 2005; 366: 225-233.

[18] Cowling BJ, Chan KH, Fang VJ, et al. Facemasks and hand hygiene to prevent influenza transmission in households: a cluster randomized trial. Ann Intern Med 2009; 151 (7): 437446.

[19] Abdul Mujeeb S, Adill MM, Altaf A, Shan SA, Luby S. Infection control practices in clinical laboratories in Pakistan. Infect Control Hosp Epidemiol 2003; 24 (2): 141-2.

[20] Hinkin J, Gammon J, Cutter J. Review of personal protection equipment used in practice. Br J Community Nurs 2008; 13 (1): 14-9.

[21] Sadoh WE, Fawole AO, Sadoh AE, Oladimeji AO, Sotiloye OS. Practice of universal precautions among health care workers. J Natl Med Assoc 2006; 98 (5): 722-6.

[22] Richard VS, Kenneth J, Cherian T, Chandy GM. Preventing transmission of blood-borne pathogens to health care workers. Natl Med J India 2000; 13 (2): 82-5.

[23] Alvarado-Ramy F, Beltrami EM. New guidelines for occupational exposure to blood-borne viruses. Cleve Clin $\mathrm{J}$ Med 2003; 70 (5): 457-65.

[24] Rotter M. Hand washing and hand disinfection. In: Mayhall CG, ed. Hospital epidemiology and infection control. 2nd ed. Philadelphia, Lippincott Williams \& Wilkins; 1999; 1339-55.

[25] Jumaa PA. Hand hygiene: simple and complex. International Journal of Infectious Disease 2005; 9: 3-14.

[26] Semmelweis I. Etiology, concept and prophylaxis of childhood fever. Eds.: Carter KC. 1st ed. Madison, WI: University of Wisconsin Press, 1983.

[27] Pittet D, Boyce JM. Hand hygiene and patient care: Pursuing the Semmelweis legacy. Lancet Infect Dis 2001; 1: 9-20.

[28] Asare A, Enweronu-Laryea CC, Newman MJ. Hand hygiene practices in a neonatal intensive care unit in Ghana. J Infect Dev Ctries 2009; 3: 352-6.

[29] Karabey S Ay P, Derbentli S, Nakipoglu Y, Esen F. Hand washing frequencies in an intensive care unit. J Hosp Infect 2002; 50: 36-41.

[30] Bischoff WE, Reynolds CN, Sessler MB, Edmond RP. Hand washing compliance by health care workers: The impact of introducing accessible, alcohol-based hand antiseptic. Arch Intern Med 2000; 160: 1017-21. 
[31] Pittet D, Allegranzi B, Storr $\mathrm{J}$ et al. Infection control as a major World Health Organization priority for developing countries. J Hosp Infect 2008; 68: 285- 92.

[32] Devnani M, Kumar R, Sharma RK, Gupta AK. A survey of hand washing facilities in the out-atient department of a tertiary care teaching hospital in India. J Infect Dev Ctries 2011; 5 (2): 114-8.

[33] Trampuz A, Widmer AF. Hand hygiene: a frequently missed lifesaving opportunity during patient care. Mayo ClinProc 2004; 79: 109-16.

[34] Whitby M, McLaws ML, Ross MW. Why health care workers don't wash their hands: a behavioural explanation. Infec Control HospEpidemiol 2006; 27: 484-92.

[35] Kesavann S, Barodawaia S, Mulley GP. Now wash your hand? A survey of hospital handwashing facilities. J Hosp Infect 1998; 40: 291-93.

[36] Amazian K, Abdelmoumene T, Sekkat S, et al. Members of NosoMedia Network (2006) Multi centre study on hand hygiene facilities and practice in the Mediterranean area: results from the NosoMed Network. J HospInfec Control 2009; 37: 851-54.

[37] Mermel LA, Josephson SL, Dempsey J, et al. Outbreak of Shigellasonnie in a clinical microbiology laboratory. J ClinMicrobiol 1997; 35: 3163-5.

[38] Caniza MA, Duenas L, Lopez B, et al. A practical guide to alcohol based hand hygiene facilities and practise in the Mediterranean area: results from the NosoMed Network. J Hosp Infect 1998; 40: 291-93.

[39] Zaragoza M, Salles M, Gomez J, et al. Hand washing with soap or alcoholic solutions? A randomized clinical trial of its effectiveness. Am J Infect Control 1999; 27: 799-806.

[40] Voss A, Widmer AF. No time for hand washing!? Hand washing versus alcoholic rub: can we afford 100\% compliance? Infect Control Hosp Epidemiol 1997; 18: 205-8.
[41] Widmer AF, Frei R. Decontamination, disinfection, sterilization. In: Murray PR, Baron EJ, Pfaller M, Tenover FC, Yolken R, editors. Manual of Clinical Microbiology. 7th ed. Washington, DC: American Society for Microbiology; 1999; 138-64.

[42] Garner JS et al. CDC Guideline for hand washing and hospital environmental control, 1985. Infection Control 1986; 7: 23143.

[43] Larson E. Guideline for use of topical antimicrobial agents. American Journal of Infection Control 1988; 16: 253-66.

[44] Larson EL. APIC Guideline for hand washing and hand antisepsis in health care settings. American Journal of Infection Control 1995; 23: 251-69.

[45] Ducel G. Prevention of hospital-acquired infections: a practical guide. Geneva, WHO, 2002.

[46] WHO/WPRO/SEARO. Practical guidelines for infection control in health care facilities. WHO/WPRO/SEARO 2004.

[47] Alex-Hart BA, Opara PI. Hand washing practices among health workers in a teaching hospital. Am J Infect Dis 2011; 7 (1): 8-15.

[48] Patrick DR et al. Residual moisture determines level of touchcontactassociated bacterial transfer following hand washing. Epidemiology of Infection 1997; 119: 319-25.

[49] Yamamoto $\mathrm{Y}$ et al. Efficiency of hand drying for removing bacteria from washed hands: comparison of paper towel drying with warm air drying. Infection Control and Hospital Epidemiology 2004; 25: 262-64.

[50] Gustafson DR et al. Effects of four hand drying methods for removing bacteria from washed hands: a randomized trial. Mayo Clinical Proceedings 2000; 75: 705-8.

[51] Ansari SA et al. Comparison of cloth, paper and warm air drying in eliminating viruses and bacteria from washed hands. American Journal of Infection Control 1991; 19: 243-9. 